ISSN 2075-9827 e-ISSN 2313-0210

Carpathian Math. Publ. 2020, 12 (1), 165-172

doi:10.15330/cmp.12.1.165-172 http://www.journals.pnu.edu.ua/index.php/cmp

Карпатські матем. публ. 2020, Т.12, №1, С.165-172

\author{
CHAIKOVS'KYI A. ${ }^{1}$, LAGODA O. ${ }^{2}$
}

\title{
BOUNDED SOLUTIONS OF A DIFFERENCE EQUATION WITH FINITE NUMBER OF JUMPS OF OPERATOR COEFFICIENT
}

\begin{abstract}
We study the problem of existence of a unique bounded solution of a difference equation with variable operator coefficient in a Banach space. There is well known theory of such equations with constant coefficient. In that case the problem is solved in terms of spectrum of the operator coefficient. For the case of variable operator coefficient correspondent conditions are known too. But it is too hard to check the conditions for particular equations. So, it is very important to give an answer for the problem for those particular cases of variable coefficient, when correspondent conditions are easy to check. One of such cases is the case of piecewise constant operator coefficient. There are well known sufficient conditions of existence and uniqueness of bounded solution for the case of one jump. In this work, we generalize these results for the case of finite number of jumps of operator coefficient. Moreover, under additional assumption we obtained necessary and sufficient conditions of existence and uniqueness of bounded solution.
\end{abstract}

Key words and phrases: difference equation, bounded solution, Banach space.

${ }^{1}$ Taras Shevchenko National University of Kyiv, 64/13 Volodymyrska str., 01601, Kyiv, Ukraine

2 Kyiv National University of Technologies and Design, 2 Nemyrovycha-Danchenka str., 01011, Kyiv, Ukraine

E-mail: chaikovskiyav@ukr.net (Chaikovs'kyi A.), oksala@ukr.net (Lagoda O.)

\section{INTRODUCTION}

Let $(X,\|\cdot\|)$ be a complex Banach space, $L(X)$ be the space of linear continuous operators in $X, I \in L(X)$ be the identity operator. Let us denote $\sigma(A)$ the spectrum of an operator $A \in L(X)$. Let us denote $S=\{z \in \mathbb{C}:|z|=1\}$ the unit circle in the complex plane.

Let us consider the difference equation

$$
x_{n+1}=A_{n} x_{n}+y_{n}, \quad n \in \mathbb{Z},
$$

where $\left\{A_{n} \mid n \in \mathbb{Z}\right\} \subset L(X),\left\{y_{n} \mid n \in \mathbb{Z}\right\} \subset X$ are known sequences, $\left\{x_{n} \mid n \in \mathbb{Z}\right\} \subset X$ is a desired sequence. In the paper we investigate the question of existence and uniqueness of a bounded solution for the equation (1).

It is known [3, chapter 7.6] the equation (1) has a unique bounded solution $\left\{x_{n} \mid n \in \mathbb{Z}\right\}$ for any bounded sequence $\left\{y_{n} \mid n \in \mathbb{Z}\right\}$ if and only if operators sequence fulfills a condition of discrete dichotomy (analogue of exponential dichotomy, which is well known in the theory of differential equations). However, checking of discrete dichotomy conditions is very hard, so we need simpler conditions of existence and uniqueness of a bounded solution for special operators sequences.

$\mathrm{y} \Delta \mathrm{K} 517.929 .2$

2010 Mathematics Subject Classification: 65Q10, 47A56.

(C) Chaikovs'kyi A., Lagoda O., 2020 
To formulate one of such conditions we need the following spectral decomposition. Assume $A \in L(X)$ and the condition $\sigma(A) \cap S=\varnothing$ is true. Then the spectrum of the operator $A$ is decomposed into two parts, one of them is inside of the unit circle $S$, the other is outside. Using the theorem about decomposition [4, p. 445] we can derive:

1) an existence of projectors $P_{-}(A), P_{+}(A) \in L(X)$ such that

$$
P_{-}(A)+P_{+}(A)=I ;
$$

2) decomposition of the space $X$ to the direct sum

$$
X=X_{-}(A) \dot{+} X_{+}(A),
$$

where $X_{-}(A)=P_{-}(A) X, X_{+}(A)=P_{+}(A) X$ are subspaces in which corresponding operators $A_{-}=P_{-}(A) A, A_{+}=P_{+}(A) A$ have spectra

$$
\sigma(A) \cap\{z \in \mathbb{C}|| z \mid<1\}, \sigma(A) \cap\{z \in \mathbb{C}|| z \mid>1\}
$$

accordingly.

I.V. Gonchar and M.F. Gorodnii investigated the equation (1) in the papers [1,2] for the case of one jump of an operator coefficient. In the paper [1] the following result was proved.

Theorem 1. Let $X$ be a complex Banach space and $G, U$ be some operators from $L(X)$, which satisfy the following conditions:

1) $\sigma(G) \cap S=\varnothing, \sigma(U) \cap S=\varnothing$;

2) $X=X_{-}(G) \dot{+} X_{+}(U)$.

Then the difference equation

$$
\begin{cases}x_{n+1}=G x_{n}+y_{n}, & n \geq 1 \\ x_{n+1}=U x_{n}+y_{n}, & n \leq 0,\end{cases}
$$

has a unique bounded in $X$ solution $\left\{x_{n}: n \in \mathbb{Z}\right\}$ for any bounded in $X$ sequence $\left\{y_{n}: n \in \mathbb{Z}\right\}$.

In the paper the result of the Theorem 1 is generalized to an equation with several jumps of an operator coefficient.

\section{MAin RESUltS}

Let us consider a special case of the equation (1) with an operator coefficient, which changes finite number of times:

$$
\begin{cases}x_{n+1}=A_{0} x_{n}+y_{n}, & n \leq 0, \\ x_{n+1}=A_{n} x_{n}+y_{n}, & 1 \leq n \leq N-1, \\ x_{n+1}=A_{N} x_{n}+y_{n}, & n \geq N .\end{cases}
$$

Here $N$ is a fixed natural number.

Assume the conditions $\sigma\left(A_{0}\right) \cap S=\varnothing, \sigma\left(A_{N}\right) \cap S=\varnothing$ are true. Then each of the operators $A_{0}, A_{N}$ produce spectral decomposition of the form (2). Let us denote

$$
\begin{array}{llll}
P_{0-}:=P_{-}\left(A_{0}\right), & P_{0+}:=P_{+}\left(A_{0}\right), & P_{N_{-}}:=P_{-}\left(A_{N}\right), & P_{N+}:=P_{+}\left(A_{N}\right), \\
X_{0-}:=X_{-}\left(A_{0}\right), & X_{0+}:=X_{+}\left(A_{0}\right), & X_{N_{-}}:=X_{-}\left(A_{N}\right), & X_{N+}:=X_{+}\left(A_{N}\right) .
\end{array}
$$


Remark 1. In a degenerate case, when one of the sets in (3) is empty, the corresponding subspace contains zero element only, so we can omit it in the direct sum. Further we assume that all these sets are nonempty. For degenerate cases statements below are true if degenerate summands are omitted.

Lemma 1. Let $\sigma\left(A_{0}\right) \cap S=\varnothing$. Then for any bounded sequence $\left\{y_{n}: n \leq 0\right\} \subset X$ all bounded solutions of the equation

$$
x_{n+1}=A_{0} x_{n}+y_{n}, \quad n \leq 0,
$$

can be obtained by the formula

$$
x_{n}=A_{0+}^{n-1} b-\sum_{k=n}^{0} A_{0}^{n-k-1} P_{0+} y_{k}+\sum_{k=-\infty}^{n-1} A_{0}^{n-k-1} P_{0-} y_{k}, \quad n \leq 1,
$$

where $b \in X_{0+}$ is an arbitrary element.

Proof. The condition $\sigma\left(A_{0+}\right) \subset\{z \in \mathbb{C}:|z|>1\}$ implies the existence of the operator $A_{0+}^{-1} \in L(X)$ and the estimate

$$
\exists C>0 \exists r \in(0,1) \forall n \geq 1\left\|A_{0+}^{-n}\right\| \leq C r^{n} .
$$

Similarly, the condition $\sigma\left(A_{0_{-}}\right) \subset\{z \in \mathbb{C}:|z|<1\}$ implies the estimate

$$
\exists C>0 \exists r \in(0,1) \forall n \geq 1\left\|A_{0-}^{n}\right\| \leq C r^{n} .
$$

So, the defined sequence (5) is bounded for any element $b \in X_{0+}$.

Let us check that the sequence (5) is a solution of the difference equation. We have

$$
\begin{aligned}
A_{0} x_{n}+y_{n} & =A_{0+}^{n} b-\sum_{k=n}^{0} A_{0}^{n-k} P_{0+} y_{k}+\sum_{k=-\infty}^{n-1} A_{0}^{n-k} P_{0-} y_{k}+P_{0+} y_{n}+P_{0-} y_{n} \\
& =A_{0+}^{(n+1)-1} b-\sum_{k=n+1}^{0} A_{0}^{(n+1)-k-1} P_{0+} y_{k}+\sum_{k=-\infty}^{(n+1)-1} A_{0}^{(n+1)-k-1} P_{0-} y_{k}=x_{n+1}, \quad n \leq 0 .
\end{aligned}
$$

On the other hand, if $\left\{z_{n}: n \geq N\right\}$ is any bounded solution and $\left\{x_{n}: n \geq N\right\}$ is any bounded solution of the form (5), the difference $\left\{r_{n}=z_{n}-x_{n}: n \geq N\right\}$, is a bounded solution of the homogeneous equation

$$
r_{n+1}=A_{0} r_{n}, \quad n \leq-1
$$

From this equation we have

$$
r_{0}=A_{0}^{-n} r_{n}, \quad n \leq-1,
$$

and, using projection operator,

$$
P_{0-} r_{0}=A_{0-}^{-n} r_{n} \rightarrow \overline{0}, \quad n \rightarrow-\infty
$$

So, $r_{0} \in X_{0+}$ and $r_{n}=A_{0+}^{n} r_{0}, n \leq-1$. We obtained that solution $\left\{z_{n}: n \leq 0\right\}$ has the form (5). This completes the proof. 
Lemma 2. Let $\sigma\left(A_{N}\right) \cap S=\varnothing$. Then for any bounded sequence $\left\{y_{n}: n \geq N\right\} \subset X$ all the bounded solutions of the equation

$$
x_{n+1}=A_{N} x_{n}+y_{n}, \quad n \geq N,
$$

can be obtained by the formula

$$
x_{n}=A_{N-}^{n-N} b+\sum_{k=N}^{n-1} A_{N}^{n-k-1} P_{N-} y_{k}-\sum_{k=n}^{+\infty} A_{N}^{n-k-1} P_{N+} y_{k}, \quad n \geq N,
$$

where $b \in X_{N-}$ is an arbitrary element.

Proof. The conditions $\sigma\left(A_{N_{+}}\right) \subset\{z \in \mathbb{C}:|z|>1\}$ and $\sigma\left(A_{N_{-}}\right) \subset\{z \in \mathbb{C}:|z|<1\}$ imply the existence of the operator $A_{N+}^{-1} \in L(X)$ and estimates similar to (6) and (7). So, the sequence (8) is bounded for any element $b \in X_{N-}$.

If we put the sequence (8) to the difference equation, we obtain

$$
\begin{aligned}
A_{N} x_{n}+y_{n} & =A_{N-}^{n-N+1} b+\sum_{k=N}^{n-1} A_{N}^{n-k} P_{N-} y_{k}-\sum_{k=n}^{+\infty} A_{N}^{n-k} P_{N+} y_{k}+P_{N-} y_{n}+P_{N+} y_{n} \\
& =A_{N-}^{n+1-N} b+\sum_{k=N}^{(n+1)-1} A_{N}^{(n+1)-k-1} P_{N-} y_{k}-\sum_{k=n+1}^{+\infty} A_{N}^{(n+1)-k-1} P_{N+} y_{k}=x_{n+1}, \quad n \geq N .
\end{aligned}
$$

Similar to proof of previous lemma, the difference $\left\{r_{n}=z_{n}-x_{n}: n \geq N\right\}$ between any bounded solution $\left\{z_{n}: n \geq N\right\}$ and bounded solution $\left\{x_{n}: n \geq N\right\}$ of the form (8), is a bounded solution of the homogeneous equation

$$
r_{n+1}=A_{N} r_{n}, \quad n \geq N,
$$

and has a form

$$
r_{n}=A_{N}^{n-N_{r_{N}}, \quad n \geq N}
$$

Since

$$
P_{N+} r_{n}=A_{N+}^{n-N} r_{N}, P_{N+} r_{N}=A_{N+}^{N-n} r_{n} \rightarrow \overline{0}, \quad n \rightarrow+\infty,
$$

we have $r_{N} \in X_{N-}$ and $r_{n}=A_{N-}^{n-N} r_{0}, n \geq 0$. So any bounded solution has the form (8). The proof is completed.

Lemma 3. Let $N \geq 2$ and $A_{N-1} A_{N-2} \cdot \ldots \cdot A_{1}$ be injection. The boundary problem

$$
\left\{\begin{array}{l}
x_{n+1}=A_{n} x_{n}+y_{n}, 1 \leq n \leq N-1 \\
P_{0-} x_{1}=v, P_{N+} x_{N}=u
\end{array}\right.
$$

has a unique solution $\left\{x_{n}: 1 \leq n \leq N\right\} \subset X$ for any $v \in X_{0_{-}}, u \in X_{N+}$ and any $\left\{y_{n}: 1 \leq n \leq N-1\right\} \subset X$ if and only if

$$
X=W \dot{+} X_{N-},
$$

where $W=\left\{A_{N-1} A_{N-2} \cdot \ldots \cdot A_{1} x: x \in X_{0+}\right\}$. 
Proof. If a solution of the problem (9) exists, then the formula

$$
x_{n}=A_{n-1} A_{n-2} \cdot \ldots \cdot A_{1} x_{1}+\sum_{k=1}^{n-2} A_{n-1} A_{n-2} \cdot \ldots \cdot A_{k+1} y_{k}+y_{n-1}, \quad 2 \leq n \leq N,
$$

is true. One can check this result by induction. We have $x_{2}=A_{1} x_{1}+y_{1}$ and

$$
\begin{aligned}
A_{n} x_{n}+y_{n}= & A_{n} A_{n-1} A_{n-2} \cdot \ldots \cdot A_{1} x_{1} \\
& +\sum_{k=1}^{n-2} A_{n} A_{n-1} A_{n-2} \cdot \ldots \cdot A_{k+1} y_{k}+A_{n} y_{n-1}+y_{n}=x_{n+1}, \quad 2 \leq n \leq N-1
\end{aligned}
$$

Necessity. Let the boundary problem has a unique solution for any bounded sequence $\left\{y_{n}: 1 \leq n \leq N-1\right\} \subset X$ and boundary conditions $v \in X_{0_{-}}, u \in X_{N_{+}}$.

Let us fix an arbitrary element $f \in X$. In case $y_{1}=y_{2}=\ldots=y_{N-2}=\overrightarrow{0}, y_{N-1}=f$, $u=v=\overrightarrow{0}$ problem (9) has the unique solution. Formula (11) gives us

$$
x_{N}=A_{N-1} A_{N-2} \cdot \ldots \cdot A_{1} x_{1}+f
$$

that is, using boundary conditions, we have $f=P_{N-} x_{N}+A_{N-1} A_{N-2} \cdot \ldots \cdot A_{1}\left(-P_{0+} x_{1}\right)$. This equality implies $f$ is the sum of elements from $W$ and $X_{N_{-}}$.

To prove uniqueness of the element's decomposition let us assume by the contrary that there are nonzero elements $u_{0} \in X_{0+}, v_{0} \in X_{N-}$ such that

$$
\overrightarrow{0}=A_{N-1} A_{N-2} \cdot \ldots \cdot A_{1} u_{0}+v_{0} .
$$

Boundary problem (9) in case $y_{1}=y_{2}=\ldots=y_{N-2}=y_{N-1}=\overrightarrow{0}, u=v=\overrightarrow{0}$ has unique solution $\left\{x_{1}, x_{2}, \ldots, x_{N-1}, x_{N}\right\}$ and

$$
x_{N}=A_{N-1} A_{N-2} \cdot \ldots \cdot A_{1} x_{1} .
$$

But adding assumption (12) we have

$$
\left(x_{N}-v_{0}\right)=A_{N-1} A_{N-2} \cdot \ldots \cdot A_{1}\left(x_{1}+u_{0}\right),
$$

so, $\left\{x_{1}+u_{0}, x_{2}, \ldots, x_{N-1}, x_{N}-v_{0}\right\}$ is another solution of the boundary problem. A contradiction.

Since $f$ is arbitrary, the required decomposition (10) is proved.

Sufficiency. Let decomposition (10) is true. For arbitrary $v \in X_{0-}, u \in X_{N+}$ and $\left\{y_{n}: 1 \leq n \leq N-1\right\} \subset X$ let us denote

$$
f:=\sum_{k=1}^{N-2} A_{N-1} A_{N-2} \cdot \ldots \cdot A_{k+1} y_{k}+y_{N-1}-u+A_{N-1} A_{N-2} \cdot \ldots \cdot A_{1} v .
$$

Due to the space decomposition we have

$$
\exists !(w, b) \in W \times X_{N-}: f=w+b
$$

or equivalently

$$
\exists !(a, b) \in X_{0+} \times X_{N-}: f=A_{N-1} A_{N-2} \cdot \ldots \cdot A_{1} a+b .
$$


Using the definition of $f$ we have

$$
\begin{aligned}
\exists !(a, b) \in X_{0+} \times X_{N-}: & \sum_{k=1}^{N-2} A_{N-1} A_{N-2} \cdot \ldots \cdot A_{k+1} y_{k}+y_{N-1} \\
& =A_{N-1} A_{N-2} \cdot \ldots \cdot A_{1}(a-v)+(b+u) .
\end{aligned}
$$

This statement implies that the problem (9) has a solution. Indeed, we can put $x_{1}=v-a$. The first boundary condition is fulfilled. Elements $x_{2}, \ldots, x_{N}$ could be obtained from (11). By comparing (11) for $n=N$ and (13) we obtain $x_{N}=b+u$ and the second boundary condition is fulfilled too.

Obtained solution is unique since for homogeneous boundary problem we have

$$
x_{N}=A_{N-1} A_{N-2} \cdot \ldots \cdot A_{1} x_{1}
$$

and $x_{N} \in X_{N-}, x_{1} \in X_{0+}$. But using space decomposition (10) we obtain $x_{N}=\overrightarrow{0}$, and using condition that operator $A_{N-1} A_{N-2} \cdot \ldots \cdot A_{1}$ is injective, we have $x_{1}=\overrightarrow{0}$, so $x_{2}=\ldots$ $=x_{N-1}=\overrightarrow{0}$. The lemma is proved.

Theorem 2. Let $\sigma\left(A_{0}\right) \cap S=\varnothing, \sigma\left(A_{N}\right) \cap S=\varnothing$ and $A_{N-1} A_{N-2} \cdot \ldots \cdot A_{1}$ be an injection. Then the equation (4) has a unique bounded solution $\left\{x_{n}: n \in \mathbb{Z}\right\} \subset X$ for any bounded sequence $\left\{y_{n}: n \in \mathbb{Z}\right\} \subset X$ if and only if

$$
X=W \dot{+} X_{N-},
$$

where $W=\left\{A_{N-1} A_{N-2} \cdot \ldots \cdot A_{1} x: x \in X_{0+}\right\}$.

Proof. Necessity. Let the equation (4) has a unique bounded solution $\left\{x_{n}: n \in \mathbb{Z}\right\} \subset X$ for any bounded sequence $\left\{y_{n}: n \in \mathbb{Z}\right\} \subset X$.

Let $\left\{b_{n}: 1 \leq n \leq N-1\right\} \subset X$ and $u \in X_{N+,} v \in X_{0-}$ be arbitrary. We will consider bounded sequence $\left\{y_{n}: n \in \mathbb{Z}\right\} \subset X$, where $y_{n}=\overline{0}, n<0 ; y_{0}=v ; y_{n}=b_{n}, 1 \leq n \leq N-1$; $y_{N}=-A_{N+} u ; y_{n}=\overline{0}, n>N$. For this sequence there exists a unique bounded solution $\left\{x_{n}: n \in \mathbb{Z}\right\} \subset X$.

By Lemma 1 the part of solution $\left\{x_{n}: n \leq 1\right\}$ has such form that $x_{1}=b+v$ where $b \in X_{0+}$. That implies

$$
P_{0-} x_{1}=v \text {. }
$$

Similarly by Lemma 2 the part of solution $\left\{x_{n}: n \geq N\right\}$ has such form that $x_{N}=b+u$, where $b \in X_{N_{-}}$, so

$$
P_{N+} x_{N}=u .
$$

Due to equalities (14) and (15) the sequence $\left\{x_{n}: 1 \leq n \leq N\right\}$ is a solution of the boundary problem (9).

Suppose by the contrary that boundary problem (9) has another solution $\left\{z_{n}: 1 \leq n \leq N\right\}$. Let

$$
\begin{array}{lll}
z_{0}=A_{0+}^{-1}\left(z_{1}-y_{1}\right), & z_{n}=A_{0+}^{n} z_{0}, & n \leq-1, \\
z_{N+1}=A_{N} z_{N}+y_{N}, & z_{n}=A_{N-}^{n-N-1} z_{N+1}, & n \geq N+2 .
\end{array}
$$

One can see that sequence $\left\{z_{n}: n \in \mathbb{Z}\right\}$ is bounded due to spectral properties of $A_{0+}$ and $A_{N-}$. This sequence is a solution of (4). Indeed, for $1 \leq n \leq N-1$ equation is true due to boundary problem and since

$$
z_{0}=A_{0+}^{-1}\left(z_{1}-y_{1}\right) \in X_{0+}, z_{N+1}=A_{N} z_{N}+y_{N}=A_{N-} z_{N}+A_{N+} u-A_{N+} u \in X_{N-},
$$


we have

$$
\begin{aligned}
& z_{1}=A_{0+} z_{0}+y_{1}=A_{0} z_{0}+y_{1}, \quad z_{n+1}=A_{0+}^{n+1} z_{0}=A_{0} A_{0+}^{n} z_{0}=A_{0} z_{n}, \quad n \leq-1, \\
& z_{N+1}=A_{N} z_{N}+y_{N}, \quad z_{n+1}=A_{N-}^{n-N_{2}} z_{N+1}=A_{N} A_{N-}^{n-N-1} z_{N+1}=A_{N} z_{n}, \quad n \geq N+1 .
\end{aligned}
$$

This solution is different from $\left\{x_{n}: n \in \mathbb{Z}\right\}$ (at least for $1 \leq n \leq N$ ). A contradiction.

Since boundary problem (9) has unique solution for any input data, Lemma 3 gives us decomposition (10).

Sufficiency. Assume that decomposition (10) is true. Let $\left\{y_{n}: n \in \mathbb{Z}\right\} \subset X$ be any bounded sequence. We will construct bounded solution of (4). This solution consists of three parts, described by Lemmas 1-3 (with intersections in $x_{1}$ and $x_{N}$ ).

By Lemma 1 for bounded sequence $\left\{y_{n}: n \leq 0\right\} \subset X$ we have

$$
x_{n}=A_{0+}^{n-1} b_{1}-\sum_{k=n}^{0} A_{0}^{n-k-1} P_{0+} y_{k}+\sum_{k=-\infty}^{n-1} A_{0}^{n-k-1} P_{0-} y_{k}, \quad n \leq 1,
$$

where $b_{1} \in X_{0+}$. In particular, $x_{1}=b_{1}+v$, where $v=\sum_{k=-\infty}^{0} A_{0}^{-k} P_{0-} y_{k} \in X_{0-}$. So, $P_{0-} x_{1}=v$.

Similarly, by Lemma 2 for bounded sequence $\left\{y_{n}: n \geq N\right\} \subset X$ we have

$$
x_{n}=A_{N-}^{n-N} b_{2}+\sum_{k=N}^{n-1} A_{N}^{n-k-1} P_{N-} y_{k}-\sum_{k=n}^{+\infty} A_{N}^{n-k-1} P_{N+} y_{k}, \quad n \geq N,
$$

where $b_{2} \in X_{N-}$. In particular, $x_{N}=b_{2}+u$, where $u=-\sum_{k=N}^{+\infty} A_{N+}^{N-k-1} y_{k} \in X_{N+}$. So, $P_{N+} x_{N}=u$.

By Lemma 3 the boundary problem (9) with defined above $u$ and $v$ has the unique solution $\left\{x_{n}: 1 \leq n \leq N\right\} \subset X$. So $x_{1}, x_{N}$ are uniquely defined by sequence $\left\{y_{n}: n \in \mathbb{Z}\right\} \subset X$. That implies that $b_{1}=P_{0+} x_{1}, b_{2}=P_{N-} x_{N}$ are uniquely defined too. So the whole solution $\left\{x_{n}: n \in \mathbb{Z}\right\} \subset X$ is uniquely defined.

Constructed solution is a unique bounded solution of (4).

Remark 2. For $N=1$ sufficiency of Theorem 2 gives us the statement of Theorem 1.

Example 1. Let $X=l_{2}, N=2$,

$$
\begin{aligned}
& A_{0} x=\left(x_{1} / 2, x_{2}(2+1 / 2), x_{3} / 4, x_{4}(2+1 / 4), x_{5} / 6, x_{6}(2+1 / 6), \ldots\right), \\
& A_{1} x=\left(x_{1}-x_{2}, x_{1}+x_{2}, x_{3}-x_{4}, x_{3}+x_{4}, x_{5}-x_{6}, x_{5}+x_{6}, \ldots\right), A_{2}=A_{0} .
\end{aligned}
$$

Then

$$
\begin{aligned}
\sigma\left(A_{0}\right) & =\sigma\left(A_{2}\right)=\{1 /(2 n), 2+1 /(2 n) \mid n \in \mathbb{N}\} \cup\{0,2\}, \\
X_{2-} & =\left\{x \in l_{2} \mid x_{2}=x_{4}=x_{6}=\ldots=0\right\}, \\
X_{0+} & =\left\{x \in l_{2} \mid x_{1}=x_{3}=x_{5}=\ldots=0\right\}, \\
W & =\left\{x \in l_{2} \mid x_{1}=-x_{2}, x_{3}=-x_{4}, x_{5}=-x_{6}, \ldots\right\} .
\end{aligned}
$$

Since $W \dot{+} X_{2-}=X$, conditions of Theorem 2 are fulfilled so for any bounded sequence $y$ the equation (4) has a unique bounded solution. 


\section{REFERENCES}

[1] Gonchar I.V. On the bounded solutions of a difference equation with a jump of an operator coefficient. Bull. T. Shevchenko National University of Kyiv 2016, 2, 25-28. (in Ukrainian)

[2] Gorodnii M.F, Gonchar I.V. On the bounded solutions of a difference equation with variable operator coefficient. Dopov. Nats. Akad. Nauk Ukr. 2016, 12, 12-16. doi:10.15407/dopovidi2016.12.012 (in Ukrainian)

[3] Henry D. Geometric Theory of Semilinear Parabolic Equations. Springer, Berlin, 1981.

[4] Riss F., Sekefal'vi-Nad' B. Lectures on functional analysis. Mir, Moscow, 1979. (in Russian)

Received 19.09.2019

Чайковський А.В., Аагода О.А. Обмежені розв'язки різницевого рівняння зі скінченною кількістю стрибків операторного коефічієнта // Карпатські матем. публ. - 2020. — Т.12, №1. — С. 165-172.

В роботі вивчається питання існування єлиного обмеженого розв'язку різницевого рівняння зі змінним операторним коефіцієнтом в банаховому просторі. Існує добре розвинена теорія відповідних рівнянь зі сталим коефіцієнтом, в рамках якої поставлене питання розв'язане в термінах спектру операторного коефіцієнта. Аля випадку змінного операторного коефіцієнта відповідні умови також відомі, проте є дуже складними для перевірки. Тому важливим $є$ дати вілповідь на поставлене питання для тих частинних випадків змінного коефіцієнта, коли відповідні умови легко перевірити. Одним з таких випадків $€$ рівняння з кусково-сталим операторним коефіцієнтом. Відомі достатні умови існування та єлиності обмеженого розв'язку Аля випадку одного стрибка. В цій роботі ці результати узагальнюються для випадку скінченного числа стрибків операторного коефіцієнта. Крім того, за додаткового припущення отримано необхідні та достатні умови існування та єАиності обмеженого розв'язку.

Ключові слова і фрази: різницеве рівняння, обмежений розв'язок, банахів простір. 